\title{
The epidemiology of sexually transmitted co-infections in HIV-positive and HIV-negative African-Caribbean women in Toronto
}

\author{
Robert S Remis ${ }^{1 *}$, Juan Liu', Mona Loutfy ${ }^{2}$, Wangari Tharao ${ }^{3}$, Anuradha Rebbapragada ${ }^{4,5}$, Stephen J Perusini ${ }^{4}$, \\ Lisungu Chieza ${ }^{3}$, Megan Saunders ${ }^{3}$, LoriAnn Green-Walker ${ }^{3}$ and Rupert Kaul ${ }^{6}$
}

\begin{abstract}
Background: HIV disproportionately affects African-Caribbean women in Canada but the frequency and distribution of sexually transmitted infections in this community have not been previously studied.

Methods: We recruited women based on HIV status through a Toronto community health centre. Participants completed a socio-behavioural questionnaire using Audio Computer Assisted Self-Interview (ACASI) and provided blood for syphilis, HIV, hepatitis B and C, herpes simplex virus type 1 (HSV-1), herpes simplex virus type 2 (HSV-2), and human cytomegalovirus (CMV) serology, urine for chlamydia and gonorrhea molecular testing and vaginal secretions for bacterial vaginosis (BV) and human papillomavirus (HPV). Differences in prevalence were assessed for statistical significance using chi-square.

Results: We recruited 126 HIV-positive and 291 HIV-negative women, with a median age of 40 and 31 years, respectively $(p<0.001)$. Active HBV infection and lifetime exposure to HBV infection were more common in HIV-positive women (4.8\% vs. $0.34 \%, p=0.004$; and $47.6 \%$ vs. $21.2 \%, p<0.0001)$, as was a self-reported history of HBV vaccination (66.1\% vs. $44.0 \%, p=0.0001)$. Classical STIs were rare in both groups; BV prevalence was low and did not vary by HIV status. HSV-2 infection was markedly more frequent in HIV-positive (86.3\%) than HIV-negative (46.6\%) women $(p<0.0001)$. Vaginal HPV infection was also more common in HIV-positive than in HIV-negative women $(50.8 \%$ vs. $22.6 \%, p<0.0001)$ as was infection with high-risk oncogenic HPV types $(48.4 \%$ vs. $17.3 \%$, $\mathrm{p}<0.0001)$.

Conclusions: Classical STIs were infrequent in this clinic-based population of African-Caribbean women in Toronto. However, HSV-2 prevalence was higher than that reported in previous studies in the general Canadian population and was strongly associated with HIV infection, as was infection with hepatitis B and HPV.
\end{abstract}

Keywords: Sexually transmitted infections, HIV, Epidemiology, African-Caribbean women, Toronto

\section{Background}

In 2011, 34 million people worldwide were infected with HIV and 1.7 million died [1]. Most HIV transmission is sexual and it is increasingly clear that common sexually transmitted bacterial and viral co-infections contribute significantly to HIV transmission risk and disease progression [2]. Infections that appear to enhance susceptibility and infectivity through sexual transmission include

\footnotetext{
*Correspondence: rs.remis@utoronto.ca

'Dalla Lana School of Public Health, University of Toronto, Toronto, Ontario, Canada

Full list of author information is available at the end of the article
}

herpes simplex virus type 2 (HSV-2), human papilloma virus (HPV), syphilis, gonorrhea, vaginal candidiasis, genital chlamydia and bacterial vaginosis (BV) [2-4]. HSV-2, human cytomegalovirus (CMV) and viral hepatitis B and $\mathrm{C}$ have been linked to more rapid disease progression and increased mortality [5-8]. Therefore, a better understanding of the epidemiology of these co-infections in HIV-affected communities is important.

Sub-Saharan Africa has a disproportionately high prevalence of both HIV and several genital co-infections that have been associated with increased HIV transmission, most notably HSV-2 and HPV [9-12]. Furthermore,

\section{Biomed Central}


African and Caribbean communities in North America and Europe have also been disproportionately affected by HIV [3], and HSV-2 infection is also very common [13].

HIV infection is frequent in African and Caribbean women in Ontario [14], with a rate 24-fold greater than other women [3]. Therefore, we aimed to characterize the epidemiology of HIV and other sexually transmitted infections (STIs) in African-Caribbean (AC) women in Toronto and to apply this knowledge to support community and public health interventions.

\section{Methods}

\section{Participants and recruitment}

The study population consisted of women 16 years of age or older from Africa and the Caribbean living in Greater Toronto. Women were eligible if they selfidentified as African or Caribbean and if they, a parent or grandparent were born in sub-Saharan Africa or the Caribbean. We recruited women attending the Women's Health in Women's Hands Community Health Centre for medical care or on-site support groups from April 2009 to October 2010. We also recruited some participants from affiliated women's shelters. Since we aimed to assess the possible associations of co-infections with HIV infection, we recruited both HIV-positive and HIV-negative attendees, with over-sampling of the former. We aimed therefore to recruit 300 HIV-negative and 300-HIV-positive women. The sample size was selected to maximize precision of STI prevalence estimates and for feasibility considerations. The study protocol was approved by the Health Research Ethics Board of the University of Toronto.

Participants completed a self-administered questionnaire using ACASI (Audio Computer Assisted Self-Interview), (Questionnaire Development System (QDS) Version 2.5, Nova Research Company, Bethesda, Maryland, USA) and provided biologic specimens. The questionnaire included demographic information, sexual behaviour (in the previous six months and lifetime, number of sexual partners and condom usage), history of STIs and other medical conditions.

\section{Sample collection}

After informed consent, we collected $20 \mathrm{ml}$ of blood by venipuncture. Participants provided a first-void urine specimen and self-collected vaginal swab for HPV molecular diagnostics. For this purpose, participants inserted the swab into the vaginal vault and inserted it into a collection tube containing transport medium. Vaginal specimens for Gram stain were collected as described by Boskey [15].

\section{Laboratory methods}

HIV testing was performed on serum by enzyme immunoassay (EIA; AxSYM HIV 1/2 gO, Abbott Diagnostics Division, Wiesbaden, Germany). If reactive, the EIA was repeated and confirmed at the Ontario Public Health Laboratory by $\mathrm{Ag} / \mathrm{Ab}$ testing (Architect $\mathrm{Ag} / \mathrm{Ab}$ Combo, Abbott Diagnostics, Abbott Park, IL, USA) and by Western blot. Serologic testing was also performed for herpes simplex, types 1 and 2 (Herpes Simplex Virus ELISA IgG, Focus Diagnostics, Cypress, CA, USA); human cytomegalovirus (CMV; AxSYM CMV IgG; Abbott Diagnostics Division, Wiesbaden, Germany); hepatitis B surface antigen (AxSYM HbSAg V2 assay, Abbott Diagnostics); hepatitis B surface and core antibodies (AxSYM Core 2.0, Abbott Diagnostics); hepatitis $\mathrm{C}$ virus antibody (HCV, AxSYM HCV Version 3.0), with serologic confirmation of HCV-positive tests (Bio-Rad Monolisa anti-HCV Plus Version 2, Bio-Rad Laboratories, Montreal, Quebec); syphilis rapid plasma reagin (RPR, Pulse Diagnostic Inc, Burlington, ON) and TPPA (Serodia TP.PA, Fujirebo Inc). Neisseria gonorrhoeae and Chlamydia trachomatis were detected in urine by nucleic acid amplification testing (ProbeTec ${ }^{\mathrm{Tm}}$ ET Amplified DNA Assay, Becton Dickinson, Franklin Lakes, NJ, USA). Bacterial vaginosis (BV) was diagnosed by the Nugent criteria using the results from a Gram stain smear of the vaginal swab [16]. A score of zero to three was considered normal, four to six was classified as abnormal vaginal flora (or intermediate), and seven to 10 was defined as BV. Trichomonas vaginalis infection was detected with the PCR methodology as described by Caliendo et al. [17]. Prior to applying this method for study samples, the sensitivity of this published PCR assay was verified in-house with a panel of known positive samples and lack of cross reactivity confirmed by testing against a panel of 40 common genitourinary bacterial species. As found by numerous other studies such as Schewbke et al., molecular testing has greater sensitivity than wet mount for clinically relevant Trichomonas vaginalis detection [18]. Human papilloma virus infection with either 13 high risk (HR) or five low risk (LR) types was detected from the vaginal swab with the HPV HR/LR HC2 test (Digene Corporation, Gaithersberg, MD, USA). The HR/LR HC2 test detects virus above 5,000 copies/ml by measuring a chemiluminescent signal (relative light units, RLU) upon hybridization of probes for LR HPV $(6,11,42,43,44)$ or HR HPV (16, $18,31,33,35,39,45,51,52,56,58,59,68)$. We calculated the ratio of RLU to establish the cutoff: specimens with 1.0 or greater were considered positive and below 1.0 negative. Participants were considered actively infected by hepatitis B if HBsAg was present and ever infected if $\mathrm{HBsAg}$, anti-HBc or anti-HBs (if not vaccinated) were detected.

\section{Statistical analysis}

The data from the ACASI questionnaire and the laboratory results were analyzed in SAS (Version 9.3, SAS, Cary, $\mathrm{NC}$ ). We examined the prevalence of STIs (and exact 
binomial 95\% confidence intervals) of co-infections stratified by HIV status. We also examined the correlates of chlamydial genital infection; in univariate analysis, four variables were significantly related to chlamydia. However, quasi-complete separation occurred and maximum likelihood estimates could not be obtained when multivariate logistic regression was performed. Therefore, we used a series of four PROC FREQ procedures with the CochranMantel-Haenszel option. In this approach, each variable was used as the predictor and the remaining three variables were used as stratifying, or controlling, variables.

\section{Results}

\section{Study population}

417 women (126 HIV-positive and 291 HIV-negative) were included in the analysis. Their demographic characteristics are shown in Table 1. HIV-negative women were younger and more likely to be single than HIV-positive women. Also, significantly more HIV-positive women were born in Africa (81.0\%) than HIV-negative women (36.4\%). The majority (59.5\%) of HIV-positive women were refugee claimants, higher than in HIV-negative women (36.4\%).

\section{Bacterial infections}

The prevalence of bacterial STIs among HIV-positive and HIV-negative women is summarized in Table 2. Chlamydia, gonorrhea and syphilis were infrequent. Only chlamydial infection prevalence differed by HIV status, being higher in HIV-negative women. BV was found in $15.4 \%$ of HIVpositive women, similar to the $17.3 \%$ among HIV-negative women.

\section{Viral infections}

The results of serologic testing for viral STIs are also shown in Table 2. All viral pathogens were more prevalent in HIV-positive women and most differences were statistically significant.

Vaginal HPV infection (either HR or LR) was detected in $50.8 \%$ of HIV-positive and $22.6 \%$ of HIV-negative women ( $\mathrm{p}<0.0001)$. Specifically, HR HPV infection was more frequent in HIV-positive women (48.4\% vs. $17.3 \%$, $\mathrm{p}<0.0001)$ and the prevalence of LR HPV infection was also higher (26.6\% vs. 9.2\%, p < 0.0001). HSV-2 infection was markedly more frequent in HIV-positive (86.3\%) than HIV-negative $(46.6 \%)$ women $(\mathrm{p}<0.0001)$.

$47.6 \%$ of HIV-positive women had serologic evidence of $\mathrm{HBV}$ infection versus $21.2 \%$ of HIV-negative women. Active HBV infection were also more common in HIVpositive women $(4.8 \%$ vs. $0.34 \%, \mathrm{p}=0.004) .66 .1 \%$ of HIV-positive compared to $44.0 \%$ of HIV-negative women reported having been vaccinated against HBV $(\mathrm{p}=0.0001)$. Among those vaccinated in whom the number of doses was known, 58.3\% (35/60) HIV-positive and
$60.0 \%$ (54/90) HIV-negative women received only one or two doses.

We also compared the prevalence of viral infections between African and Caribbean women. While prior HBV infection was more common in African women, both HIV-positive $(52.9 \%$ vs. $23.8 \%, \mathrm{p}=0.015)$ and HIVnegative $(33.3 \%$ vs. $17.1 \%, \mathrm{p}=0.004)$, no significant differences were seen in the other viral infections.

\section{Covariates of chlamydial infection}

The prevalence of chlamydia among HIV-negative women varied by age in years: $15-19,8.7 \% ; 20-24,11.5 \% ; 25-29$, $3.8 \%$; $30-34,2.4 \%$; and $35+, 0.0 \%$. The results of the correlation analysis of chlamydia are presented in Table 3. Among HIV-negative women, the prevalence of chlamydia was higher in younger $(10.7 \%$ in those $15-24$ years old compared to $1.4 \%$ in those $\geq 25$ years old, $\mathrm{p}=0.0013$ ) and sexually active women $(5.5 \%$ in those had had sex in the previous six months compared to $0.0 \%$ in those had not, $\mathrm{p}=0.015)$. Chlamydia was more common in women born in Canada (8.3\%) than in Africa (1.0\%), $(\mathrm{p}=0.03)$. After controlling for other variables indicated in Table 4, chlamydial infection was associated with sex in the previous six months $(\mathrm{p}=0.024)$ and younger age $(\mathrm{p}=0.059)$. After controlling for age, sexual behaviour and region of birth, chlamydia was not significantly associated with HIV status.

\section{Covariates of bacterial vaginosis}

BV was not associated with HIV status but was associated with younger age in both HIV-positive and HIV-negative women. Among HIV-positive women, the prevalence of BV varied by age (in years): $15-24,50.0 \%(1 / 2) ; 25-44$, $21.2 \%(18 / 67)$; and $45+, 0.0 \%(0 / 36)$ ( $\mathrm{p}$ for trend $=0.005)$. The same trend of decreasing BV prevalence by age was observed among HIV-negative women: 15-24, 27.0\%; 25-44, 13.2\%; and 45+, 15.5\% ( $\mathrm{p}$ for trend $=0.034$ ). HIV-negative women reporting sex in the previous six months had a higher prevalence of BV (23.5\%) than those who did not $(10.2 \%),(p=0.008)$.

\section{Discussion}

The African and Caribbean communities in Ontario are disproportionately affected by HIV but, until now, little was known about the prevalence of other STIs which may be important in HIV acquisition and progression. In our study, we recruited women on the basis of HIV status since our goal was not to assess prevalence of HIV, but rather the relationship of co-infections with HIV in this population. We found that classical sexually transmitted infections, i.e. gonorrhea, chlamydia and syphilis, were infrequent. BV was less common than expected and the prevalence did not vary by HIV status. However, persistent (or potentially persistent) viral infections 
Table 1 Demographic characteristics among HIV-positive and HIV-negative African-Caribbean women in Toronto

\begin{tabular}{|c|c|c|c|}
\hline & HIV-positive & HIV-negative & $p$ value \\
\hline Total participants & 126 & 291 & \\
\hline \multicolumn{4}{|l|}{ Age (years) } \\
\hline Mean & 40.3 & 33.9 & $<0.0001^{\mathrm{a}}$ \\
\hline Median (IQR) & $40(34-46)$ & $31(24-42)$ & \\
\hline $15-24$ & $2(1.6 \%)$ & $78(26.8 \%)$ & \\
\hline $25-34$ & $30(23.8 \%)$ & $96(33.0 \%)$ & \\
\hline $35-44$ & $58(46.0 \%)$ & $59(20.3 \%)$ & \\
\hline $45+$ & $36(28.6 \%)$ & $58(19.9 \%)$ & \\
\hline \multicolumn{4}{|l|}{ Education } \\
\hline No education & $4(3.2 \%)$ & $7(2.4 \%)$ & NS \\
\hline Some/completed elementary school & $11(8.8 \%)$ & $31(10.7 \%)$ & \\
\hline Some/completed secondary school & $46(36.8 \%)$ & $118(40.8 \%)$ & \\
\hline Some/completed college/university & $61(48.8 \%)$ & $119(41.2 \%)$ & \\
\hline Some/completed graduate education & $3(2.4 \%)$ & $14(4.8 \%)$ & \\
\hline \multicolumn{4}{|l|}{ Marital status } \\
\hline Married/common-low & $22(18.0 \%)$ & $72(25.4 \%)$ & $<0.0001$ \\
\hline Separated/divorced/widowed & $57(46.7 \%)$ & $49(17.3 \%)$ & \\
\hline Single & $43(35.2 \%)$ & $163(57.4 \%)$ & \\
\hline \multicolumn{4}{|l|}{ Annual household income } \\
\hline Less $\$ 10,000$ & $38(35.2 \%)$ & $102(55.1 \%)$ & $<0.0001$ \\
\hline$\$ 10,000-\$ 19,999$ & $37(34.3 \%)$ & $29(15.7 \%)$ & \\
\hline$\$ 20,000-\$ 49,999$ & $30(27.8 \%)$ & $34(18.4 \%)$ & \\
\hline$\$ 50,000$ or more & $3(2.8 \%)$ & $20(10.8 \%)$ & \\
\hline \multicolumn{4}{|l|}{ Language spoken } \\
\hline $\mathrm{N}$ & 118 & 278 & \\
\hline English & $103(87.3 \%)$ & $252(90.3 \%)$ & NS \\
\hline French & $15(12.7 \%)$ & $32(11.5 \%)$ & NS \\
\hline Spanish & $0(0.0 \%)$ & $3(1.1 \%)$ & NS \\
\hline Other & $44(37.3 \%)$ & $49(17.6 \%)$ & $<0.0001$ \\
\hline \multicolumn{4}{|l|}{ Region of birth } \\
\hline Africa & $102(81.0 \%)$ & $106(36.4 \%)$ & $<0.0001^{b}$ \\
\hline Caribbean & $21(16.7 \%)$ & $131(45.0 \%)$ & \\
\hline Canada & $2(1.6 \%)$ & $50(17.2 \%)$ & \\
\hline Other & $1(0.8 \%)$ & $4(1.4 \%)$ & \\
\hline \multicolumn{4}{|l|}{ Immigration status at first arrival in Canada } \\
\hline Landed/permanent resident & $25(20.7 \%)$ & $58(25.1 \%)$ & $0.0008^{b}$ \\
\hline Refugee claimant & $72(59.5 \%)$ & $84(36.4 \%)$ & \\
\hline Temporary worker & $1(0.8 \%)$ & $3(1.3 \%)$ & \\
\hline Visitor & $17(14.0 \%)$ & 71 (30.7\%) & \\
\hline Student & $2(1.7 \%)$ & $6(2.6 \%)$ & \\
\hline Non-status & 4 (3.3\%) & 9 (3.9\%) & \\
\hline
\end{tabular}

were more frequent in African-Caribbean women in general, particularly in HIV-positive women, with the prevalence of herpes, HPV and CMV being much higher than described in other Canadian populations [19-21].
While our study cannot demonstrate the causal direction of these associations, both HSV-2 and HPV have been found to increase HIV susceptibility [2,4], implying that education and other interventions, including HPV 
Table 2 Prevalence of bacterial and viral pathogens among HIV-positive and HIV-negative African-Caribbean women in Toronto

\begin{tabular}{|c|c|c|c|c|c|c|c|}
\hline & & HIV-p & & & HIV-ne & & $p$ value \\
\hline & Tested & Positive & $\begin{array}{c}\text { Prevalence \% } \\
\left(95 \% \mathrm{Cl}^{\mathrm{a}}\right)\end{array}$ & Tested & Positive & $\begin{array}{c}\text { Prevalence \% } \\
(95 \% \mathrm{Cl})\end{array}$ & \\
\hline Chlamydia & 123 & 0 & $0.0 \%(0.0-2.9 \%$ & 286 & 11 & $3.8 \%(1.9-6.8 \%)$ & $0.039^{b}$ \\
\hline Gonorrhea & 124 & 0 & $0.0 \%(0.0-2.9 \%)$ & 285 & 0 & $0.0 \%(0.0-1.3 \%)$ & NS \\
\hline Syphilis & 126 & 1 & $0.79 \%(0.02-4.3 \%)$ & 291 & 1 & $0.34 \%(0.01-1.9 \%)$ & NS \\
\hline Bacterial vaginosis & 123 & 19 & $15.4 \%(9.6-23.1 \%)$ & 283 & 49 & $17.3 \%(13.1-22.2 \%)$ & NS \\
\hline Abnormal vaginal flora & 123 & 42 & $34.1 \%(25.8-43.2 \%)$ & 283 & 84 & $29.7 \%(24.4-35.4 \%)$ & NS \\
\hline Trichomonas vaginalis & 124 & 9 & 7.3\% (3.4-13.3\%) & 286 & 13 & $4.5 \%(2.4-7.6 \%)$ & NS \\
\hline Yeast & 123 & 9 & $7.3 \%$ (3.3-13.4\%) & 283 & 19 & $6.7 \%(4.1-10.3 \%)$ & NS \\
\hline HSV-1 & 123 & 111 & $90.2 \%$ (83.6-94.6\%) & 290 & 254 & $87.6 \%$ (83.2-91.2\%) & NS \\
\hline HSV-2 & 124 & 107 & $86.3 \%$ (79.0-91.8\%) & 290 & 135 & $46.6 \%$ (40.7-52.5\%) & $<0.0001$ \\
\hline Cytomegalovirus & 126 & 125 & $99.2 \%(95.7-100 \%)$ & 291 & 274 & $94.2 \%(90.8-96.6 \%)$ & 0.018 \\
\hline High risk HPV, vaginal & 124 & 60 & $48.4 \%$ (39.3-57.5\% & 283 & 49 & $17.3 \%$ (12.9-21.7\% & $<0.0001$ \\
\hline $\mathrm{HCV}$ & 126 & 5 & $4.0 \%(1.3-9.0 \%)$ & 290 & 4 & $1.4 \%(0.38-3.5 \%)$ & NS \\
\hline HBV infected ${ }^{c}$ & 126 & 6 & $4.8 \%(1.8-10.1 \%)$ & 291 & 1 & $0.34 \%(0.01-1.9 \%)$ & $0.004^{b}$ \\
\hline HBV ever $^{d}$ & 126 & 60 & $47.6 \%(38.7-56.7 \%)$ & 283 & 60 & $21.2 \%(16.6-26.4 \%)$ & $<0.0001$ \\
\hline HBV vaccination & 109 & 72 & $66.1 \%(56.4-74.9 \%)$ & 248 & 109 & $44.0 \%(37.7-50.4 \%)$ & 0.0001 \\
\hline
\end{tabular}

${ }^{\mathrm{a}} 95 \%$ exact binomial confidence interval.

${ }^{\mathrm{b}}$ Fisher's Exact Test.

Infected with HBV: HBsAg, with or without other HBV markers.

dEver infected with HBV: HBsAg, anti-HBc, or anti-HBs if not vaccinated for HBV.

Table 3 Prevalence of chlamydia and predicting factors among HIV-positive and HIV-negative African-Caribbean women in Toronto

\begin{tabular}{|c|c|c|c|c|c|c|}
\hline & \multicolumn{2}{|c|}{ HIV-positive } & \multicolumn{2}{|c|}{ HIV-negative } & \multicolumn{2}{|c|}{ Total } \\
\hline & $\mathbf{N}$ & $\%$ chlamydia & $\mathrm{N}$ & $\%$ chlamydia & $\mathrm{N}$ & $\%$ chlamydia \\
\hline & 123 & $0.0 \%$ & 286 & $3.8 \%$ & 409 & $2.7 \%$ \\
\hline \multicolumn{7}{|l|}{ Age (years) } \\
\hline $15-24$ & 2 & $0.0 \%$ & 75 & $10.7 \%$ & 77 & $10.4 \%$ \\
\hline$\geq 25$ & 121 & $0.0 \%$ & 211 & $1.4 \%$ & 332 & $0.90 \%$ \\
\hline \multirow[t]{2}{*}{$\overline{p \text { value }}$} & & & & $0.0013^{\mathrm{a}}$ & & $<0.0001^{\mathrm{a}}$ \\
\hline & & $\mathrm{CMH}^{\mathrm{b}}$ controlling & us: $p$ & & & 0.0014 \\
\hline \multicolumn{7}{|c|}{ Had sex in previous 6 months } \\
\hline Yes & 58 & $0.0 \%$ & 163 & $5.5 \%$ & 221 & $4.1 \%$ \\
\hline No & 62 & $0.0 \%$ & 100 & $0.0 \%$ & 162 & $0.0 \%$ \\
\hline \multirow[t]{2}{*}{$p$ value } & & & & $0.015^{\mathrm{a}}$ & & $0.012^{\mathrm{a}}$ \\
\hline & & $\mathrm{CMH}$ controlling & $u s: p v$ & & & 0.017 \\
\hline \multicolumn{7}{|c|}{ Region of birth } \\
\hline Canada & 2 & $0.0 \%$ & 48 & $8.3 \%$ & 50 & $8.0 \%$ \\
\hline Caribbean & 20 & $0.0 \%$ & 129 & $4.7 \%$ & 149 & $4.0 \%$ \\
\hline Africa & 100 & $0.0 \%$ & 105 & $1.0 \%$ & 205 & $0.5 \%$ \\
\hline Other & 1 & $0.0 \%$ & 4 & $0.0 \%$ & 5 & $0.0 \%$ \\
\hline \multirow[t]{2}{*}{$p$ value } & & & & $0.13^{\mathrm{a}}$ & & $0.012^{a}$ \\
\hline & & $\mathrm{CMH}$ controlling & $u s: p v$ & & & 0.15 \\
\hline
\end{tabular}

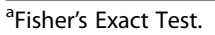

${ }^{\mathrm{b}}$ Cochran-Mantel-Haenzel test. 
Table 4 Correlates of chlamydial infection, univariate and multivariate ${ }^{a}$

\begin{tabular}{|c|c|c|c|c|c|}
\hline & Chlamydia-positive & Chlamydia-negative & Chlamydia-prevalence & p value ${ }^{b}$ & Adjusted $\mathrm{p}$ value \\
\hline \multicolumn{6}{|l|}{ HIV status } \\
\hline HIV-positive & 0 & 120 & $0.0 \%$ & 0.062 & 0.25 \\
\hline HIV-negative & 9 & 254 & $3.4 \%$ & & \\
\hline \multicolumn{6}{|l|}{ Age (years) } \\
\hline $15-24$ & 6 & 69 & $8.0 \%$ & 0.002 & 0.059 \\
\hline$\geq 25$ & 3 & 305 & $0.97 \%$ & & \\
\hline \multicolumn{6}{|c|}{ Had sex in previous 6 months } \\
\hline Yes & 9 & 212 & $4.1 \%$ & 0.012 & 0.024 \\
\hline No & 0 & 162 & $0.0 \%$ & & \\
\hline \multicolumn{6}{|c|}{ Region of birth } \\
\hline Canada & 4 & 45 & $8.2 \%$ & 0.018 & 0.48 \\
\hline Caribbean & 4 & 132 & $2.9 \%$ & & \\
\hline Africa & 1 & 192 & $0.52 \%$ & & \\
\hline Other & 0 & 5 & $0.0 \%$ & & \\
\hline
\end{tabular}

${ }^{\text {aAmong }} 383$ participants with all data for the variables above.

${ }^{b}$ Fisher's Exact Test.

${ }^{c}$ Cochran-Mantel-Haenszel controlling other variables in the table.

vaccination, might both reduce the high viral STI burden and reduce HIV transmission in these communities. Currently, quadrivalent HPV vaccine (Gardasil) is offered free of charge to Grade 8 students in a school-based public health program in Ontario. Many high-risk types of HPV not infrequent in the population studied here (data not shown) are not included in the present vaccine. Including several of these in an expanded vaccine would be desirable.

HBV infection was prevalent in both HIV-positive and HIV-negative African-Caribbean women though HBV vaccination rates were suboptimal in both groups. HBV vaccine is safe, effective and cost-effective and efforts should be made to reinforce HBV vaccination to protect African-Caribbean women against this serious infection.

Our finding of a low prevalence of most bacterial STI pathogens suggests that they may not play a major role in HIV transmission in the African and Caribbean communities in Toronto. However, given the availability of effective antibiotic treatment for these pathogens and the fact that many of these infections resolve without treatment, the current status of participants may not reflect past infections. Thus, these pathogens could still have played a role in HIV acquisition, especially since HIVpositive women could have been infected before arriving in Canada [22].

Interestingly, we found a significantly higher prevalence of chlamydial infection in HIV-negative compared to HIV-positive women. This was due to younger age and more frequent sex rather than HIV status and we observed no association of chlamydia with HIV positivity after adjusting for age and sexual behaviour [23]. The rate of the chlamydial infection among HIV-negative women was significantly higher among women under 25 years; likely due to both increased sexual activity and the greater biologic susceptibility. This suggests that there is room for more systematic chlamydial screening in this population. At this prevalence, chlamydial screening in this population is probably cost-beneficial $[24,25]$.

The low prevalence of BV was unexpected, as was the lack of association with HIV status. BV has been associated with HIV transmission, both with HIV acquisition in women [26] and with HIV transmission to male partners of HIV-positive women [27]. Furthermore, previous studies have found that women of African and Caribbean descent have an increased prevalence of BV, whether residing in Africa [28] or in North America [29] and that BV is more prevalent in HIV-positive women [30]. In our study, the prevalence of BV in both groups was less than $20 \%$, slightly lower than the $23 \%$ observed in white women in the USA, and much lower than the $52 \%$ in African-American women in the same study [29]. The reason for the low BV prevalence is not clear, but may relate to the recruitment of women from a clinic-based setting where treatment of common genital infections was available.

While bacterial co-infections were not common, viral STIs were prevalent and strongly associated with HIV status. The prevalence of vaginal HPV (any type) of 22.6\% we observed in HIV-negative women was almost double the global average of $11.7 \%$ [31] and the $12.7 \%$ in Ontario [31], but very similar to the pooled average of $24 \%$ reported in women in sub-Saharan Africa [10]. As expected, the prevalence of vaginal HPV infection in HIV-positive women was more than double than that of their HIV-negative counterparts. In particular, we found 
a strong association of HPV and oncogenic HR HPV with HIV infection status and, among HIV-positive women, the majority of HPV infections were HR strains. While we cannot ascertain whether these HR HPV infections are persistent given the cross-sectional design, our findings reinforce the need for regular cervical cancer screening in this population. Furthermore, we used HybirdCapture2 test to detect HPV DNA present at 5,000 copies or higher. Thus, it is possible that a small subset of individuals might be infected by HPV and yet shed HPV DNA at a level that is below the threshold of detection. The frequency of such an occurrence is unknown. Finally, participants self-sampled for all genital diagnostics, i.e. using either urine or vaginal swabs, and direct cervical samples were not obtained. Vaginal selfsampling is considered a reliable surrogate for clinician collected cervical sampling for HPV DNA detection [32].

We observed a prevalence of HSV-2 among HIVnegative women of just under $50 \%$, very similar to the $48 \%$ seen in Black, non-Hispanic women in the US [13] but well above the general population prevalence of $21 \%$ or less in women in both the US [13] and Ontario [21]. A recent systematic survey of the health of Canadians carried out in 2009-2011 found a weighted prevalence of HSV-2 of $16.1 \%$ in women aged 14 to 59 years [33]. As with previous studies, we found that HSV-2 infection was very strongly associated with HIV infection. It should be noted that the positive predictive value (PPV) of the Focus HSV2 ELISA test may be poor in populations with a low prevalence of $\mathrm{HSV}-2$, at just $38 \%$ in a student population with an HSV-2 prevalence of under 4\% [34]. However, the PPV was over $93 \%$ in a population with a higher HSV-2 prevalence of over 40\% [35]. Therefore, we believe that the high HSV-2 prevalence in our participants $(48 \%$ in the HIV-uninfected women) means that this is less likely to be a concern in our study.

Our cross-sectional study format does not allow us to assess the temporal nature of the relationship between HIV and these viral infections, i.e. whether HPV and HSV-2 infection were acquired before or after HIV infection. It is well established that HSV-2 increases HIV susceptibility [36], while the reverse association is not clear. Furthermore, a strong age association of HSV-2 infection was seen in the HIV-negative participants in our study (data not shown) but this was not apparent in HIV-positive women. Therefore, it is plausible that preceding HSV-2 infection led to enhanced HIV acquisition after subsequent sexual exposure, resulting in a high HSV-2 prevalence in all ages of HIV-positive women. While vaginal HPV infection may also enhance HIV susceptibility [37], HIV infection is known to increase both the incidence and duration of subsequent HPV infection [38], making it harder to hypothesize regarding the temporal nature of this association.
Participants were recruited from a community health centre in downtown Toronto. Thus, subjects may not be representative of African-Caribbean population in Toronto. However, they do represent a broad sample of women by age, region of birth, and education, Furthermore the distribution by these variables is very similar to that of African- and Caribbean-born women in Toronto according to the 2006 Canada Census (data not shown). We were unable to recruit our initial target of $300 \mathrm{HIV}-$ positive women. Nevertheless, the number recruited provided sufficient power to compare these populations for most of the variables of interest. As in all studies of this type, the information on sexual behaviour was selfreported and therefore subject to inaccuracy and potential bias. In general, women may be less likely to report risky sexual behaviours, especially if they are perceived as socially undesirable given the pervasive information promoting condom use.

\section{Conclusions}

Overall, our study found that classical STIs were infrequent in women from the African and Caribbean community in Toronto, Canada, implying that enhanced screening and treatment is not likely to reduce HIV transmission, with the possible exception of chlamydial infection in younger women. However, persistent, or potentially persistent, HSV-2 and HPV viral infections were much more prevalent than in the general population in Ontario, emphasizing the vulnerability of African and Caribbean women to HIV infection and the need to effectively reduce their exposure to HIV.

\section{Abbreviations}

ACASI: Audio computer assisted self-interview; BV: Bacterial vaginosis; CMV: Human cytomegalovirus; QDS: Questionnaire Development System; HPV: Human papillomavirus; HR: High risk; HSV-1: Herpes simplex virus type 1; HSV-2: Herpes simplex virus type 2; LR: Low risk.

\section{Competing interests}

The authors declare that they have no competing interests.

\section{Authors' contributions}

$R S R, R K, M L$ and WT designed the study. JL analyzed the data. LC recruited the participants and assured the data and sample collection. MS and LAGW supported the study at the clinic and helped to coordinate the subject recruitment. AR and S.PP carried out the HPV laboratory analyses. All authors contributed to and approved the final manuscript.

\section{Acknowledgements}

We acknowledge the help of clinical support staff at Women's Health in Women's Hands Community Health Centre and Sanja Huibner at the University Health Network. The study was funded by an Emerging Team Grant from the Canadian Institutes of Health Research, Canada (Grant number HET-85518).

\section{Author details}

${ }^{1}$ Dalla Lana School of Public Health, University of Toronto, Toronto, Ontario, Canada. 'Women's College Research Institute, Women's College Hospital, University of Toronto, Toronto, Ontario, Canada. ${ }^{3}$ Women's Health in Women's Hands Community Health Centre, Toronto, Ontario, Canada. ${ }^{4}$ Public Health Laboratory - Toronto, Public Health Ontario, Toronto, Ontario, 
Canada. ${ }^{5}$ Department of Laboratory Medicine and Pathobiology, University of Toronto, Toronto, Ontario, Canada. ${ }^{6}$ Department of Medicine, University Health Network, University of Toronto, Toronto, Ontario, Canada.

Received: 27 May 2013 Accepted: 12 November 2013

Published: 17 November 2013

\section{References}

1. UNAIDS: 2012 Report on the global AIDS epidemic. Geneva: UNAIDS; 2012.

2. Cohen MS: HIV and sexually transmitted diseases: lethal synergy. Top HIV Med 2004, 12(4):104-107.

3. Kaul R, Cohen CR, Chege D, Yi TJ, Tharao W, McKinnon LR, Remis R, Anzala $\mathrm{O}$, Kimani J: Biological factors that may contribute to regional and racial disparities in HIV prevalence. Am J Reprod Immunol 2011, 65(3):317-324.

4. Galvin SR, Cohen MS: The role of sexually transmitted diseases in HIV transmission. Nat Rev Microbiol 2004, 2(1):33-42.

5. Gianella S, Anderson CM, Vargas MV, Richman DD, Little SJ, Morris SR, Smith DM: CMV DNA in semen and blood is associated with higher levels of proviral HIV DNA. J Infect Dis 2013, 207(6):898-902.

6. Greub G, Ledergerber B, Battegay M, Grob P, Perrin L, Furrer H, Burgisser P, Erb P, Boggian K, Piffaretti JC, et al: Clinical progression, survival, and immune recovery during antiretroviral therapy in patients with HIV-1 and hepatitis C virus coinfection: the Swiss HIV cohort study. Lancet 2000, 356(9244):1800-1805.

7. Griffiths PD: CMV as a cofactor enhancing progression of AIDS. J Clin Virol 2006, 35(4):489-492

8. Nikolopoulos GK, Paraskevis D, Hatzitheodorou E, Moschidis Z, Sypsa V, Zavitsanos X, Kalapothaki V, Hatzakis A: Impact of hepatitis B virus infection on the progression of AIDS and mortality in HIV-infected individuals: a cohort study and meta-analysis. Clin Infect Dis 2009, 48(12):1763-1771.

9. Abu-Raddad LJ, Magaret AS, Celum C, Wald A, Longini IM Jr, Self SG, Corey $L$ : Genital herpes has played a more important role than any other sexually transmitted infection in driving HIV prevalence in Africa. PLOS One 2008, 3(5):e2230

10. Bruni L, Diaz M, Castellsagué X, Ferrer E, Bosch FX, de Sanjosé S: Cervical human papillomavirus prevalence in 5 continents: meta-analysis of 1 million women with normal cytological findings. J Infect Dis 2010, 202(12):1789-1799

11. Weiss H: Epidemiology of herpes simplex virus type 2 infection in the developing world. Herpes 2004, 11(Suppl 1):24A-35A.

12. Weiss HA, Buvé A, Robinson NJ, Van Dyck E, Kahindo M, Anagonou S, Musonda R, Zekeng L, Morison L, Caraël M, et al: The epidemiology of HSV-2 infection and its association with HIV infection in four urban African populations. AIDS 2001, 15(Suppl 4):S97-S108.

13. Xu F, Sternberg MR, Gottlieb SL, Berman SM, Markowitz LE, Forhan SE, Taylor LD: Seroprevalence of herpes simplex virus type 2 among persons aged 14-49 years -United States, 2005-2008. MMWR 2010, 59(15):456-459.

14. Remis RS, Swantee C, Liu J: Report on HIV/AIDS in Ontario, 2009. Ontario Ministry of Health and Long Term Care; 2012. Available at http://www. ohemu.utoronto.ca/doc/PHERO2009 report final.pdf.

15. Boskey ER, Atherly-Trim SA, O'Campo PJ, Strobino DM, Misra DP: Acceptability of a self-sampling technique to collect vaginal smears for gram stain diagnosis of bacterial vaginosis. Womens Health Issues 2004, 14(1):14-18.

16. Nugent RP, Krohn MA, Hillier SL: Reliability of diagnosing bacterial vaginosis is improved by a standardized method of gram stain interpretation. J Clin Microbiol 1991, 29(2):297-301.

17. Caliendo AM, Jordan JA, Green AM, Ingersoll J, Diclemente RJ, Wingood GM: Real-time PCR improves detection of Trichomonas vaginalis infection compared with culture using self-collected vaginal swabs. Infect Dis Obstet Gynecol 2005, 13(3):145-150.

18. Schwebke JR, Hobbs MM, Taylor SN, Sena AC, Catania MG, Weinbaum BS, Johnson AD, Getman DK, Gaydos CA: Molecular testing for trichomonas vaginalis in women: results from a prospective U.S. clinical trial. J Clin Microbiol 2011, 49(12):4106-4111.

19. Joseph SA, Beliveau C, Muecke CJ, Rahme E, Soto JC, Flowerdew G, Johnston L, Langille D, Gyorkos TW: Risk factors for cytomegalovirus seropositivity in a population of day care educators in Montréal, Canada. Occup Med 2005, 55(7):564-567.
20. Moore RA, Ogilvie G, Fornika D, Moravan V, Brisson M, Amirabbasi-Beik M, Kollar A, Burgess T, Hsu R, Towers L, et al: Prevalence and type distribution of human papillomavirus in 5,000 British Columbia women-implications for vaccination. Cancer Causes Control 2009, 20(8):1387-1396.

21. Howard M, Sellors JW, Jang D, Robinson NJ, Fearon M, Kaczorowski J, Chernesky M: Regional distribution of antibodies to herpes simplex virus type 1 (HSV-1) and HSV-2 in men and women in Ontario, Canada. J Clin Microbiol 2003, 41(1):84-89.

22. Rice BD, Elford J, Yin Z, Delpech VC: A new method to assign country of HIV infection among heterosexuals born abroad and diagnosed with HIV. AIDS 2012, 26(15):1961-1966.

23. Holmes KK: Sexually transmitted diseases. 4th edition. New York: McGraw-Hill; 2008.

24. Adams EJ, Turner KM, Edmunds WJ: The cost effectiveness of opportunistic Chlamydia screening in England. Sex Transm Infect 2007, 83(4):267-275.

25. Hu D, Hook EW 3rd, Goldie SJ: Screening for Chlamydia trachomatis in women 15 to 29 years of age: a cost-effectiveness analysis. Ann Intern Med 2004, 141(7):501-513.

26. Atashili J, Poole C, Ndumbe PM, Adimora AA, Smith JS: Bacterial vaginosis and HIV acquisition: a meta-analysis of published studies. AIDS 2008, 22(12):1493-1501.

27. Cohen CR, Lingappa JR, Baeten JM, Ngayo MO, Spiegel CA, Hong T, Donnell D, Celum C, Kapiga S, Delany S, Bukusi EA: Bacterial vaginosis associated with increased risk of female-to-male HIV-1 transmission: a prospective cohort analysis among African couples. PLoS Med 2012, 9(6):e1001251.

28. Thoma ME, Gray RH, Kiwanuka N, Wang MC, Sewankambo N, Wawer MJ: The natural history of bacterial vaginosis diagnosed by gram stain among women in Rakai, Uganda. Sex Transm Dis 2011, 38(11):1040-1045.

29. Allsworth JE, Peipert JF: Prevalence of bacterial vaginosis: 2001-2004 national health and nutrition examination survey data. Obstet Gynecol 2007, 109(1):114-120.

30. Sewankambo N, Gray RH, Wawer MJ, Paxton L, McNaim D, WabwireMangen F, Serwadda D, Li C, Kiwanuka N, Hillier SL, et al: HIV-1 infection associated with abnormal vaginal flora morphology and bacterial vaginosis. Lancet 1997, 350(9077):546-550.

31. Sellors JW, Mahony JB, Kaczorowski J, Lytwyn A, Bangura H, Chong S, Lorincz A, Dalby DM, Janjusevic V, Keller JL: Prevalence and predictors of human papillomavirus infection in women in Ontario, Canada. Survey of HPV in Ontario women (SHOW) group. CMAJ 2000, 163(5):503-508.

32. Safaeian M, Kiddugavu M, Gravitt PE, Ssekasanvu J, Murokora D, Sklar M, Serwadda D, Wawer MJ, Shah KV, Gray R: Comparability of self-collected vaginal swabs and physician-collected cervical swabs for detection of human papillomavirus infections in Rakai, Uganda. Sex Transm Dis 2007, 34(7):429-436.

33. Roterman M, Langlois KA, Severini A, Totten S: Prevalence of Chlamydia trachomatis and herpes simplex virus type 2: results from the 2009 to 2011 Canadian health measures survey. Health Rep 2013, 24(4):10-15.

34. Mark HD, Nanda JP, Roberts J, Rompalo A, Melendez JH, Zenilman J: Performance of focus ELISA tests for HSV-1 and HSV-2 antibodies among university students with no history of genital herpes. Sex Transm Dis 2007, 34(9):681-685.

35. Turner KR, Wong EH, Kent CK, Klausner JD: Serologic herpes testing in the real world: validation of new type-specific serologic herpes simplex virus tests in a public health laboratory. Sex Transm Dis 2002, 29(7):422-425.

36. Glynn JR, Biraro S, Weiss HA: Herpes simplex virus type 2: a key role in HIV incidence. AIDS 2009, 23(12):1595-1598

37. Houlihan CF, Larke NL, Watson-Jones D, Smith-McCune KK, Shiboski S, Gravitt PE, Smith JS, Kuhn L, Wang C, Hayes R: Human papillomavirus infection and increased risk of HIV acquisition: a systematic review and meta-analysis. AIDS 2012, 26(17):2211-2222.

38. Mbulawa ZZ, Marais DJ, Johnson LF, Coetzee D, Williamson AL: Impact of human immunodeficiency virus on the natural history of human papillomavirus genital infection in South African men and women. $J$ Infect Dis 2012, 206(1):15-27.

doi:10.1186/1471-2334-13-550

Cite this article as: Remis et al:: The epidemiology of sexually

transmitted co-infections in HIV-positive and HIV-negative AfricanCaribbean women in Toronto. BMC Infectious Diseases 2013 13:550. 